\title{
Genetic or Pharmacological Reduction of PERK Enhances Cortical-Dependent Taste Learning
}

\author{
Hadile Ounallah-Saad, ${ }^{1 \star}$ (DVijendra Sharma, ${ }^{1 \star}$ Efrat Edry, ${ }^{2}$ and Kobi Rosenblum ${ }^{1,2}$ \\ ${ }^{1}$ Sagol Department of Neurobiology, ${ }^{2}$ Center for Gene Manipulation in the Brain, University of Haifa, Haifa 3498838, Israel
}

Protein translation initiation is controlled by levels of eIF2 $\alpha$ phosphorylation (p-eIF2 $\alpha$ ) on Ser51. In addition, increased p-eIF $2 \alpha$ levels impair long-term synaptic plasticity and memory consolidation, whereas decreased levels enhance them. Levels of p-eIF $2 \alpha$ are determined by four kinases, of which protein kinase RNA-activated (PKR), PKR-like endoplastic reticulum kinase (PERK), and general control nonderepressible 2 are extensively expressed in the mammalian mature brain. Following identification of PERK as the major kinase to determine basal levels of p-eIF $2 \alpha$ in primary neuronal cultures, we tested its function as a physiological constraint of memory consolidation in the cortex, the brain structure suggested to store, at least in part, long-term memories in the mammalian brain. To that aim, insular cortex (IC)-dependent positive and negative forms of taste learning were used. Genetic reduction of PERK expression was accomplished by local microinfusion of a lentivirus harboring PERK Short hairpin RNA, and pharmacological inhibition was achieved by local microinfusion of a PERK-specific inhibitor (GSK2606414) to the rat IC. Both genetic reduction of PERK expression and pharmacological inhibition of its activity reduced p-eIF $2 \alpha$ levels and enhanced novel taste learning and conditioned taste aversion, but not memory retrieval. Moreover, enhanced extinction was observed together with enhanced associative memory, suggesting increased corticaldependent behavioral plasticity. The results suggest that, by phosphorylating eIF2 $\alpha$, PERK functions in the cortex as a physiological constraint of memory consolidation, and its downregulation serves as cognitive enhancement.

Key words: consolidation; eIF2 $\alpha$; gustatory cortex; protein synthesis; taste

\section{Introduction}

De novo protein synthesis is crucial for memory consolidation in which short-term memory is transformed to long-term memory (LTM; for review, see Gkogkas et al., 2010). Translation regulation of newly synthesized proteins occurs during both the initiation and the elongation phases, and both phases are regulated during memory consolidation (Belelovsky et al., 2005, 2007; Costa-Mattioli et al., 2007; Antion et al., 2008; Hoeffer and Klann, 2010; Jiang et al., 2010). In addition, several signal transduction cascades regulate different components of the translation machinery during memory consolidation (Gal-Ben-Ari et al., 2012).

Translation initiation is controlled by the phosphorylation on Ser51 of eukaryotic initiation factor $2 \alpha$ (eIF $2 \alpha$; Sonenberg and

\footnotetext{
Received May 25, 2014; revised Sept. 10, 2014; accepted Sept. 12, 2014.
}

Author contributions: H.O.-S., V.S., and K.R. designed research; H.O.-S., V.S., and E.E. performed research; E.E. contributed unpublished reagents/analytic tools; H.O.-S., V.S., and K.R. analyzed data; H.O.-S., V.S., and K.R. wrote the paper.

This work was supported by German-Israeli Foundation Deutsche-Israeli Projektkooperation (R03971/1-1), Morasha (Israeli Science Foundation Legacy Heritage 1315/09), European Union Seventh Framework Program EUROSPIN (Contract HEALTH-F2-2009-241498), and the Wolfson Charitable Trust to K.R.; the Ministry of Science and Technology (Eshkol fellowship) to H.O.-S.; and the Israeli Planning and Budgeting Committee Program Fellowships for Outstanding Post-Doctoral Fellows from China and India to V.S. We thank laboratory members of K.R., specifically Dr. Shunit Gal Ben-Ari for critical reading of the manuscript and primary culture generation. We also thank Dr. Axten J. and G.S.K. for providing the PERK small-molecule inhibitor GSK2606414.

*H.O.-S. and V.S. contributed equally to this work.

The authors declare no competing financial interests.

Correspondence should be addressed to Prof. K. Rosenblum, Sagol Department of Neurobiology, University of Haifa, Haifa 3498838, Israel. E-mail: kobir@psy.haifa.ac.il.

DOI:10.1523/JNEUROSCI.2117-14.2014

Copyright $\odot 2014$ the authors $\quad 0270-6474 / 14 / 3314624-09 \$ 15.00 / 0$
Dever, 2003). eIF2 $\alpha$ phosphorylation results in decreased translation of most mRNAs but paradoxically increases translation of mRNAs harboring several initiation sites on the $5^{\prime} \mathrm{UTR}$, such as ATF4 and BACE1 (Hooper et al., 2007; O'Connor et al., 2008). The switch from short-term to long-term synaptic plasticity and memory is bidirectionally regulated by eIF $2 \alpha$ phosphorylation $(\mathrm{p}$-eIF $2 \alpha)$ and reduction in p-eIF2 $\alpha$ levels results in memory enhancement (Costa-Mattioli et al., 2007).

In the brain, eIF $2 \alpha$ can be phosphorylated by three well described kinases: (1) protein kinase RNA-activated (PKR, a double-stranded RNA-dependent protein kinase); (2) PKR-like endoplasmic reticulum kinase (PERK); and (3) general control nonderepressible 2 (GCN2). Meanwhile, the dephosphorylation of eIF2 $\alpha$ is mediated via PP1c and the adaptor protein GADD34 (for a recent review, see Gkogkas et al., 2010).

One robust learning procedure to study molecular mechanisms of memory consolidation is the taste learning procedure in rodents (Elkobi et al., 2008; Barki-Harrington et al., 2009; GalBen-Ari and Rosenblum, 2011; Inberg et al., 2013). De novo protein synthesis in the insular cortex (IC) is essential for the formation of long-term taste memory (Merhav et al., 2006; Yefet et al., 2006; Merhav and Rosenblum, 2008) and the role of mammalian target of rapamycin (mTOR) pathway (Belelovsky et al., 2009) and of the elongation factor eEF2 (Gildish et al., 2012) in taste memory formation has been previously reported. On the initiation level, novel taste learning results in reduction in p-eIF $2 \alpha$ levels (Stern et al., 2013), and is enhanced in both eIF2 $\alpha$ S51A KI mice (CostaMattioli et al., 2007) and PKR KO mice (Stern et al., 2013). 
The role of PERK in cognitive function, which has been studied mainly by using the PERK CKO mice, has been implicated in behavioral inflexibility (Trinh et al., 2012). PERK has also been suggested to play a pivotal role in neurodegenerative diseases involving the unfolded protein response (UPR), such as prion disease (Moreno et al., 2012) and Alzheimer's disease (Ma et al., 2013). However, its role in cortical-dependent learning remains unclear.

We therefore, aimed first to determine which kinase is the dominant one in determining p-eIF $2 \alpha$ levels under basal conditions in primary neuronal cells, and to study the role of PERK in taste learning using positive as well as negative taste learning procedures [incidental taste learning and conditioned taste aversion (CTA), respectively] by either locally inhibiting its activity using a specific inhibitor, GSK2606414 (Axten et al., 2012), or by decreasing its expression levels using a specific short hairpin RNA (shRNA) lentivirus.

\section{Materials and Methods}

\section{Tissue culture}

NIH3T3 mouse fibroblasts were propagated in DMEM, adjusted to contain $1.5 \mathrm{~g} / \mathrm{l}$ sodium bicarbonate, $0.1 \mathrm{~mm}$ nonessential amino acids, and 1 mM sodium pyruvate. All media were supplemented with $10 \%$ fetal bovine serum (FBS), $2 \mathrm{~mm}$ L-glutamine, $10 \mathrm{U}$ penicillin, $10 \mu \mathrm{g}$ of strepto$\mathrm{mycin} / \mathrm{ml}$, and $30 \mu \mathrm{g} / \mathrm{ml}$ of cefuroxime antibiotics. Cell lines were maintained at $37^{\circ} \mathrm{C}$ with $5 \% \mathrm{CO}_{2}$ and subcultured twice weekly. Primary cultures of cortical neurons were prepared from the cortex of 1-d-old neonatal mice or rats. Briefly, the dissected tissue was digested using trypsin and DNase in digestion solution ( $137 \mathrm{~mm} \mathrm{NaCl}, 5 \mathrm{~mm} \mathrm{KCl}, 7 \mathrm{~mm}$ $\mathrm{Na}_{2} \mathrm{HPO}_{4}, 25 \mathrm{~mm}$ HEPES, pH 7.2), and was further mechanically dissociated using a silicon-coated Pasteur pipette with DNase-supplemented dissociation solution ( $12 \mathrm{~mm} \mathrm{MgSO}_{4} * 7 \mathrm{H}_{2} \mathrm{O}$ in HBSS). HBSS with $20 \%$ FBS was added to the supernatant, and centrifuged for $10 \mathrm{~min}$ at $1500 \times$ $g\left(4^{\circ} \mathrm{C}\right)$. The supernatant was aspirated and the pellet was resuspended in HBSS. This step was repeated twice. The final pellet was resuspended in MEM with $10 \%$ horse serum (MEM-10\%) and cells were seeded on polyethyleneimine-coated plates. The cells were grown in MEM-10\% for 1 week, and were later kept for $3 \mathrm{~d}$ in in MEM with $10 \%$ horse serum and $8 \mu \mathrm{M}$ cytosine arabinoside $(3 \mu \mathrm{M})$ to halt glial growth, and were then maintained for another in MEM containing B27 (Invitrogen, according to manufacturer's instructions) medium to support neuronal growth, before viral infection. All media used contained $2 \mathrm{mM}$ L-glutamine and $0.5 \mu \mathrm{g}$ insulin.

\section{Animals}

Adult, male Wistar Hola rats, aged $\sim 60$ d, weighing 200-250 g (Harlan) were used in all experiments. They were housed individually on a $12 / 12 \mathrm{~h}$ light/dark cycle and provided with water and standard rodent chow ad libitum. Animals were handled according to approved protocols and animal welfare regulations of the University of Haifa Institutional Ethics Committee.

\section{Infusion of recombinant lentivirus harboring PERK shRNA to adult rat IC}

For virus infusions, rats were first anesthetized with ketamine $(120 \mathrm{mg} /$ $\mathrm{kg}$ ) and xylazine $(6 \mathrm{mg} / \mathrm{kg}$ ) and placed into a stereotactic frame (Steolting Europe). Using a 32 gauge stainless steel injector attached to a stereotactic infusion pump, rats received $1 \mu$ l of lentivirus encoding PERK shRNA or lentivirus harboring a scrambled sequence over $10 \mathrm{~min}$ into the IC (anteroposterior, $+1.2 \mathrm{~mm}$ relative to bregma; lateral, $\pm 5.5 \mathrm{~mm}$; ventral, $-6.0 \mathrm{~mm}$ ) according to the atlas of Paxinos and Watson (2006). The injector was left in place for $5 \mathrm{~min}$ before and after infusion to minimize fluid retraction. The rats were allowed $\geq 7 \mathrm{~d}$ to recover from the surgery before any behavior experiments were conducted.

Cannulation and microinfusion of PERK inhibitor GSK2606414 The rats were cannulated as described by Barki-Harrington et al. (2009). Briefly, the rats were anesthetized by administration of equithesin $(0.3$ $\mathrm{ml} / 100 \mathrm{~g}$ ), comprising 2.12\% (w/v) $\mathrm{MgSO}_{4}, 10 \%$ (v/v) ethanol, 39.1\% (v/v) propyleneglycol, $0.98 \%(\mathrm{w} / \mathrm{v})$ sodium pentobarbital, and $4.2 \%$ $(\mathrm{w} / \mathrm{v})$ chloral hydrate. They were restrained in a stereotactic frame (Steolting Europe) and stainless steel guide cannulae (23 gauge) were bilaterally implanted into the IC, angled at (with reference to bregma) anteroposterior $+1.2 \mathrm{~mm}$, lateral $\pm 5.5 \mathrm{~mm}$, and ventral $5.0 \mathrm{~mm}(1 \mathrm{~mm}$ ahead of injecting cannula). Two skull screws were inserted into the skull, and acrylic dental cement was applied to secure the cannulae in position. A 28 gauge stylus was inserted into each guide cannula to prevent clogging. The rats were allowed 1 week in individual cages to recover from the surgery, before the experimental manipulation. PERK inhibitor GSK2606414 (Axten et al., 2012) was dissolved in DMSO and further diluted in saline to a final DMSO concentration of $0.5 \%$. A total of $1 \mu \mathrm{lof}$ 100 nм GSK2606414 or vehicle was infused bilaterally. For microinfusion, the stylus was removed from the guide cannula and a 28 gauge injection cannula was carefully inserted, to extend $1.0 \mathrm{~mm}$ beyond the tip of the guide cannula. The injection cannula was connected via PE20 tubing to a Hamilton syringe (Hamilton) driven by a CMA/100 microinjection pump (Carnegie Medicine), to provide an injection rate of 1 $\mu \mathrm{l} / \mathrm{min}$. After $1 \mathrm{~min}$ of infusion, the injection cannula was kept in the guide cannula for an additional minute to minimize dragging of infused solutes along the injection tract. Locations of cannula were verified in 30 $\mu \mathrm{m}$ coronal sections.

\section{Lentivirus production, infection, and expression}

shRNA constructs directed against PERK/PKR/GCN2 were purchased from Sigma-Aldrich and OriGene (for PERK and PKR shutdown, we used Sigma-Aldrich clones no. TRCN28772 and no. TRCN 26988, respectively, in pLKO.1-puro-CMVTurboGFP plasmids; for GCN2 we used OriGene clone no. GI572502). The scrambled and GCN2 shRNA sequences were subcloned into the lentiviral plasmid pFUGW6 for coexpression of shRNA driven by U6 promoter, and EGFP driven by ubiquitin promoter. Using Blast2Sequences, the PERK mouse sequence was found to be highly homologous to PERK rat sequence, and the efficacy of PERK shRNA (clone no. TRCN28772) to shut down PERK expression was the same in both mouse and rat primary cultures. Lentiviral particles were produced according to Lois et al., 2002 at the Center for Gene Manipulation in the Brain (University of Haifa, http://cgmb.haifa.ac.il/). Briefly, lentiviral expression, packaging, and envelope plasmid vectors were cotransfected into the 293FT cell line (Invitrogen) and allowed to express and form viral particles for $48 \mathrm{~h}$. The medium was collected and the viral particles were purified and concentrated by multiple centrifugation steps, dissolved in sterile PBS, aliquoted, and stored at $-80^{\circ} \mathrm{C}$ until further use. To confirm that shRNA expression attenuates kinasespecific levels, we infected 3T3 cells and primary cultures by adding five MOIs of the virus (stock titer was $10^{\wedge} 9 / \mathrm{ml}$ transducing units into the culture medium overnight). The medium was replaced the day after infection, and cells were allowed 1 week to achieve stable expression levels. The cells were harvested in $2 \times$ sample buffer (10\% glycerol, $2 \%$ SDS, $0.5 \mathrm{M}$ Tris- $\mathrm{HCl}$ ), and immunoblot analysis was performed as described below. In vivo, lentivirus was injected into the IC as described above, and allowed to express for $7 \mathrm{~d}$. To test the effect on learning, we injected shRNA-expressing or control viruses harboring a scrambled sequence $7 \mathrm{~d}$ before CTA was performed. To test the effect on retrieval, CTA was performed first, and after $7 \mathrm{~d}$ the shRNA-expressing or control virus was injected. Aversion to the novel taste, $0.3 \% \mathrm{NaCl}$, was measured as described below.

\section{Preparation of total samples for biochemical analysis}

At the end of the behavioral procedure, the brains were removed and snap-frozen in liquid nitrogen. Gustatory cortex punches were made using a cryostat (Leica) according to injection coordinates and were homogenized by 30 strokes in a glass-Teflon homogenizer in a lysis buffer containing 10 mm HEPES, pH 7.4, 2 mm EDTA, 2 mM EGTA, 0.5 mm DTT, $1 \%$ phosphatase inhibitor mixture (3-P0044, Sigma-Aldrich), and $1 \%$ protease inhibitor mixture (p2714, Sigma-Aldrich). Protein content was determined with the BCA Protein Assay Kit (GE Healthcare). Appropriate volumes of $2 \times$ SDS sample buffer (10\% glycerol, $5 \%$ $\beta$-mercaptoethanol, $4 \%$ SDS, $120 \mathrm{~mm}$ Tris- $\mathrm{HCl}, \mathrm{pH}$ 6.8) were added to the homogenates, and samples were boiled for $5 \mathrm{~min}$ and stored at $-80^{\circ} \mathrm{C}$ till further analysis. 


\section{Western blotting}

Samples were prepared in SDS sample buffer, subjected to 7.5-10\% SDSPAGE and Western blot analysis. Each lane was loaded with equal amounts of protein $(10 \mu \mathrm{g})$. After transfer to a nitrocellulose membrane, the blots were blocked for $1 \mathrm{~h}$ with 4\% BSA in Tris-buffered saline plus $0.5 \%$ Tween 20 (TBST) at room temperature. They were then incubated overnight with the primary antibodies PKR (1:1000; Santa Cruz Biotechnology), eIF2 $\alpha$ (1:1000; Cell Signaling Technology), p-(Ser51) eIF2 $\alpha$ (1:1000; Invitrogen), GCN2, PERK (both 1:1000; Cell Signaling Technology), $\beta$-actin (1: 3000; Santa Cruz Biotechnology), and $\beta$-tubulin (1: 30,000; Sigma-Aldrich). The blots were then subjected to three $5 \mathrm{~min}$ washing steps in TBST, after which they were incubated with the corresponding HRP-conjugated secondary antibodies [goat anti-rabbit (IgG), goat anti-mouse (IgG), or rabbit anti-goat (IgG; 1:10,000; Millipore Bioscience Research Reagents)] for $1 \mathrm{~h}$ at room temperature followed by three 10 min washes with TBST. Immunodetection was performed with the enhanced chemiluminescence EZ-ECL Kit (Biological Industries). The immunoblots were quantified with a CCD camera and Quantity One software (Bio-Rad). Each sample was measured relative to the background. Phosphorylation levels were calculated as the ratio between chemiluminescence values of the antibody directed against the phosphoproteins and those of the antibody directed against the phosphorylation state-independent forms of the proteins.

\section{Behavioral procedures}

Attenuation of neophobia (novel taste learning). The rats were separated into individual housing cages and underwent a $3 \mathrm{~d}$ water-restriction training session, in which once a day for $20 \mathrm{~min}$, they were offered $20 \mathrm{ml}$ of water from two pipettes, each containing $10 \mathrm{ml}$. On the fourth day, the control group received water and the experimental group was exposed to a novel taste [0.1\% (w/v) sodium saccharin; Rosenblum et al., 1993]. After 2 successive days of water-restriction training, the rats were tested in a multiple-choice test involving two pipettes of water and two of saccharin. The multiple-choice test was repeated during 3 successive days. The behavioral data are presented in terms of preference index, expressed as a percentage $([\mathrm{ml}$ saccharin $/(\mathrm{ml}$ water $+\mathrm{ml}$ saccharin $)] \times$ $100)$ in which the quantities are those consumed during each test. The behavioral procedure is illustrated in the top part of Figures 2, 3, and 4.

CTA. CTA experiments were performed as described previously (Elkobi et al., 2008; Stern et al., 2013). Briefly, after 3 d of training to drink from pipettes as described above, rats on the fourth day received either water or $0.3 \% \mathrm{NaCl}$ (the conditioned stimulus), and $40 \mathrm{~min}$ after termination of drinking both groups received the unconditioned stimulus in the form of an intraperitoneal injection of the malaise-inducing agent $\mathrm{LiCl}(0.075 \mathrm{M}, 2 \%$ of body weight). The rats then received water for $2 \mathrm{~d}$, and then underwent a taste preference test that involved a 20 min exposure to a choice of water or $0.3 \% \mathrm{NaCl}$ in different pipettes. The aversion index to the novel taste is defined as the amount of water consumed divided by the total fluid consumption, expressed as a percentage ([ (water volume/(water $+\mathrm{NaCl})$ volume $] \times 100)$. The behavioral procedure is illustrated in the top part of Figures 2, 3, and 4.

Water T-maze position discrimination and arm reversal procedure. The position discrimination and reversal learning task were conducted in a water T-maze pool. In position discrimination learning, rats were required to learn left-right discrimination with the choice of one of the arms reinforced by escaping onto a platform, and for reversal learning the two reinforcement contingencies were switched so that the choice of the opposite arm was reinforced. At the start of each trial, the rat was placed in the starting arm, facing the wall opposite the cross piece, and allowed to swim and choose between the two arms. If the rat chose the correct arm, it was allowed to remain on the platform for $10 \mathrm{~s}$, after which it was removed from the maze to a holding cage for the $10 \mathrm{~s}$ intertrial interval. If the wrong arm was chosen, the rat was confined to the arm for $\sim 20 \mathrm{~s}$ and then removed from the maze to a holding cage for the duration of the intertrial interval. Each rat was trained until it reached a criterion of five consecutive correct trials. After $24 \mathrm{~h}$, each rat was first tested on the position discrimination of the previous day in a probe trial, in which the platform is removed from the maze. If the reinforced arm was chosen, then the rat was trained for the reversal of that discrimination, i.e., the platform was moved to the opposite arm; if the nonreinforced arm was chosen, the rat was retrained as on the previous day, and tested again $24 \mathrm{~h}$ later. The rat was then trained on the reversal of this discrimination, i.e., the platform was located in the opposite arm, until the criterion was met. Other than that, training continued exactly as on the previous day. The arm chosen on each trial and the number of trials to meet the criterion on the initial discrimination and reversal were recorded for each rat.

\section{Statistical analysis}

Data are expressed as mean \pm SEM. For normally distributed data, statistical significance was determined with repeated-measures one-way ANOVA. For post hoc comparison, the least significant difference test was used with a level of $p<0.05$. For abnormally distributed data, we used Friedman's test followed by post hoc analysis using Wilcoxon signed-rank tests with Bonferroni's correction applied, $p<0.05$ for statistically significant differences. Student's $t$ test was used to examine the differences between groups.

\section{Results \\ PERK is the main kinase to determine basal levels of p-eIF2 $\alpha$} in neurons

First, we hypothesized that local reduction in the expression of the different eIF $2 \alpha$ kinases would reduce p-eIF $2 \alpha$ in neurons. Toward that end, we generated viral vectors expressing shRNA sequences that can efficiently reduce the expression of three of the dominant eIF $2 \alpha$-regulating kinases in the brain (PERK, PKR, and GCN2; Fig. 1A). Target validation was performed in 3T3 cells, which were infected with viruses expressing three different shRNA cassettes for either one of the kinases or a control cassette harboring a scrambled sequence (Edry et al., 2011). The data presented are of the shRNA cassettes that could competently and specifically shut down kinase expression, compared with the control virus (PERK, GCN2, and PKR levels were reduced by $79 \pm$ $18.1 \%, 97 \pm 19.3 \%$, and $57 \pm 7.2 \%$, respectively; $n=4, t_{(6)}=$ $-3.569, p=0.02$ for PERK reduction; $t_{(6)}=-5.312, p=0.01$ for GCN2 reduction; and $t_{(6)}=-2.596, p=0.04$ for $\mathrm{PKR}$ reduction, $t$ test; Fig. $1 B$ ). As an additional control for the specificity of each shRNA cassette, we examined its effect on the expression of the other kinases, and found that each shRNA cassette is indeed specific to its target and does not affect the expression of the other kinases (data not shown).

Next, the effect of reduction in expression of each kinase on phosphorylation of eIF2 $\alpha$ on Ser51 residue in 3T3 cells was tested (Fig. $1 C)$. Of the three kinases, PERK knockdown resulted in the strongest reduction in p-eIF2 $\alpha$ levels $\left(63 \pm 4.9 \%, n=4, t_{(6)}=5.196, p=\right.$ $0.007, t$ test), whereas the knockdown of PKR or GCN2 resulted in a moderate nonsignificant reduction in p-eIF $2 \alpha$ levels ( $35 \pm 6.2 \%$ and $35 \pm 19.1 \%$ respectively, $p>0.05, n=4)$. Furthermore, the effect of the reduction of expression levels of each kinase on the p-eIF2 $\alpha$ was examined in primary neuronal culture and, similar to the results in 3T3 cells, PERK knockdown, but not that of PKR or GCN2, resulted in a significant reduction in p-eIF $2 \alpha$ levels $(59 \pm 7.5 \%$ reduction in p-eIF2 $\alpha$ levels by PERK shRNA lentivirus, compared with scrambled shRNA lentivirus, $p=0.03 ; t_{(8)}=7.091$, no effect in PKR or GCN2 knockdown, $n=4-10$; Fig. $1 D)$.

\section{Local inhibition of PERK in the IC using GSK2606414 reduces p-eIF $2 \alpha$ levels and enhances both positive and negative forms of taste memory}

Novel taste learning induces a reduction in p-eIF $2 \alpha$ in the IC (Stern et al., 2013). We tested the hypothesis that local inhibition of the eIF $2 \alpha$ kinase PERK in the IC would reduce p-eIF $2 \alpha$ levels, and would mediate enhancement of taste memory. Stereotactic injection of PERK inhibitor GSK2606414 ( $1 \mu \mathrm{l}, 100 \mathrm{nM}$; Axten et al., 2012) to the IC resulted in a significant reduction in p-eIF $2 \alpha$ 
A

\begin{tabular}{|l|lllllll|l|}
\hline 5'UTR & Flap & U6 & Scrambled & Ub & EGFP & WRE & 3'UTR \\
\hline 5'UTR & Flap & U6 & GCN2 shRNA & Ub & EGFP & WRE & 3'UTR & \multicolumn{1}{c|}{} \\
\hline 5'UTR & Flap & U6 & PERK shRNA & CMV & EGFP & hPGK & PuroR & 3'UTR \\
\hline 5'UTR & Flap & U6 & PKR shRNA & CMV & EGFP & hPGK & PuroR & 3'UTR \\
\hline
\end{tabular}

C
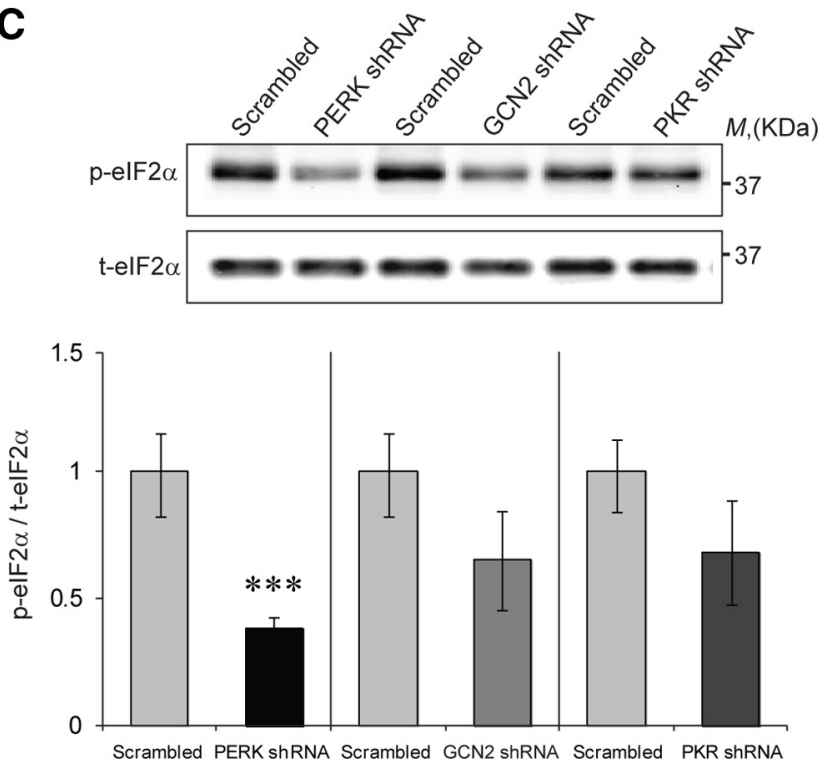

B
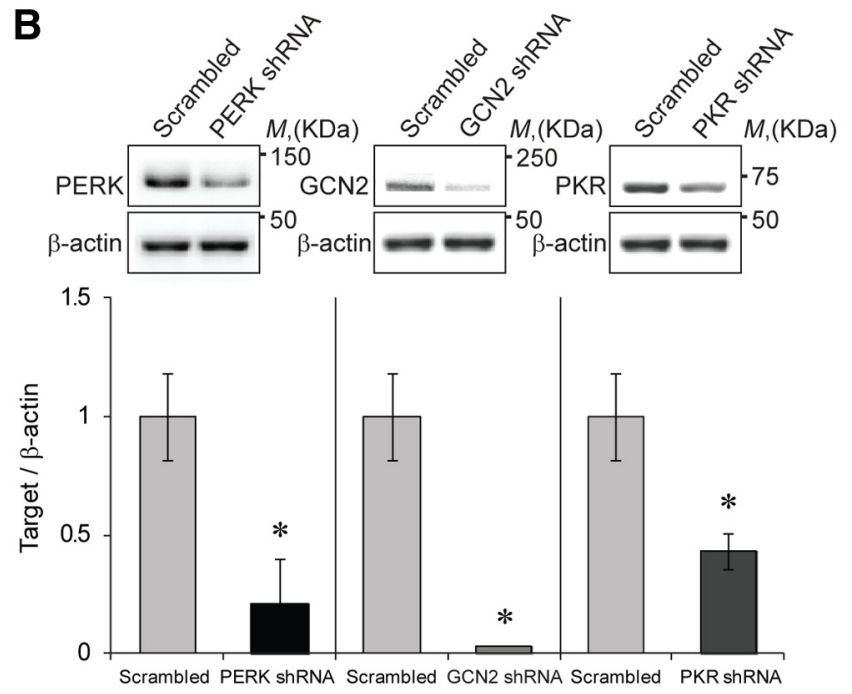

D

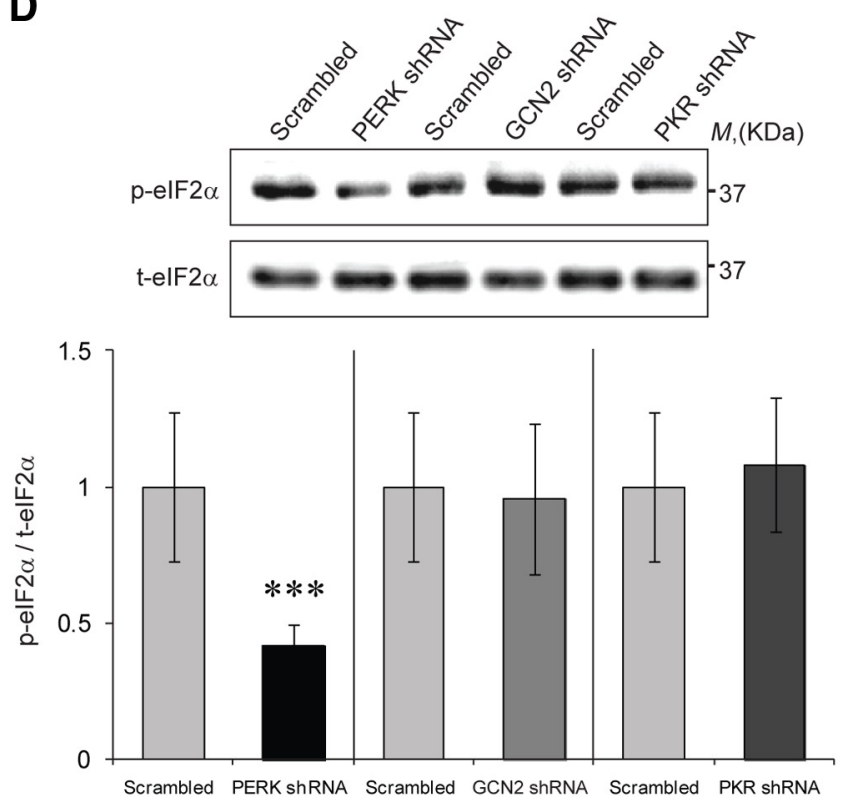

Figure 1. PERK is the major kinase to determine basal levels of p-elF2 $\alpha$. $\boldsymbol{A}$, Schematic description of the plasmids used to generate lentiviruses. $\boldsymbol{B}$, Immunoblot quantification of the specific target is expressed as the ratio of target-specific antibody/actin. $n=4,{ }^{*} p=0.02$ for PERK, $p=0.01$ for GCN2, and $p=0.04$ for PKR. C, $p$-elF2 $\alpha$ is expressed as the ratio between anti-phospho antibody (Ser51) and anti-protein antibody; results were normalized to scrambled sequence control vector (SCR)-infected 3 T3 cells (Scrambled; $n=4,{ }^{* * *} p=0.007$, Student's $t$ test). D, p-elF2 $\alpha$ is expressed as the ratio between anti-phospho antibody (Ser51) and anti-protein antibody; results were normalized to SCR-infected primary neuronal cells $\left(n=5-10\right.$, $\left.{ }^{* * *} p=0.03\right)$. Data are mean \pm SEM.

levels by $40 \%$ compared with vehicle $\left[t_{(28)}=-2.251, p=0.032, t\right.$ test, $n=15$ (each group), data not shown; representative image indicating the guiding cannula placement and the injection site is shown in Fig. $2 A$ ]. In addition to the reduction in p-eIF $2 \alpha$, we observed a $30 \%$ reduction in ATF4 protein levels (data not shown, $t_{(30)}=2.217, n=16$ in each group, $p=0.034, t$ test).

To test the effect of PERK inhibition on the behavioral level, PERK inhibitor ( $1 \mu$ l of GSK2606414, $100 \mathrm{nM}$ ) was injected to the IC $20 \mathrm{~min}$ before exposure to a novel taste, in either an incidental taste learning procedure $(0.1 \%$ saccharin $)$ or a CTA procedure using $0.3 \% \mathrm{NaCl}$, coupled to $0.075 \mathrm{M} \mathrm{LiCl}$ intraperitoneal injection, as described previously (Rosenblum et al., 1993). Memory was assessed $2 \mathrm{~d}$ after learning.

In the incidental taste learning procedure, PERK inhibition resulted in better memory of the novel taste $(0.1 \%$ saccharin) in the PERK inhibitor-injected group compared with the vehicle-injected group on test day 1 , as demonstrated by the higher elevation in the preference index $(83 \pm 2.2 \%$ vs $64 \pm 11.1 \%$, respectively; Fig. $2 B$; $n=8$ in each group, $t_{(14)}=2.505, p=0.04, t$ test). In the CTA procedure, PERK inhibitor-injected animals had better memory (higher aversion) than vehicle-injected animals ( $72 \pm 3.5 \%$ vs $54 \pm$ $6.5 \%, n=8$ in each group, $t_{(14)}=2.325, p=0.04, t$ test). However, extinction of CTA was not affected by the single injection of PERK inhibitor during CTA (repeated-measures ANOVA; Fig. 2C). Total drinking volumes were similar in both experimental groups throughout the behavioral procedure (data not shown).

\section{PERK knockdown in the IC decreases p-eIF2 $\alpha$, enhances} positive and negative forms of taste memory, and increases behavioral plasticity

Using the viral vector tested in cells, we next wanted to determine whether knockdown of PERK expression levels would result in decreased p-eIF $2 \alpha$ levels and enhanced memory. Our hypothesis was that a prolonged reduction in PERK expression and p-eIF2 $\alpha$ 
A
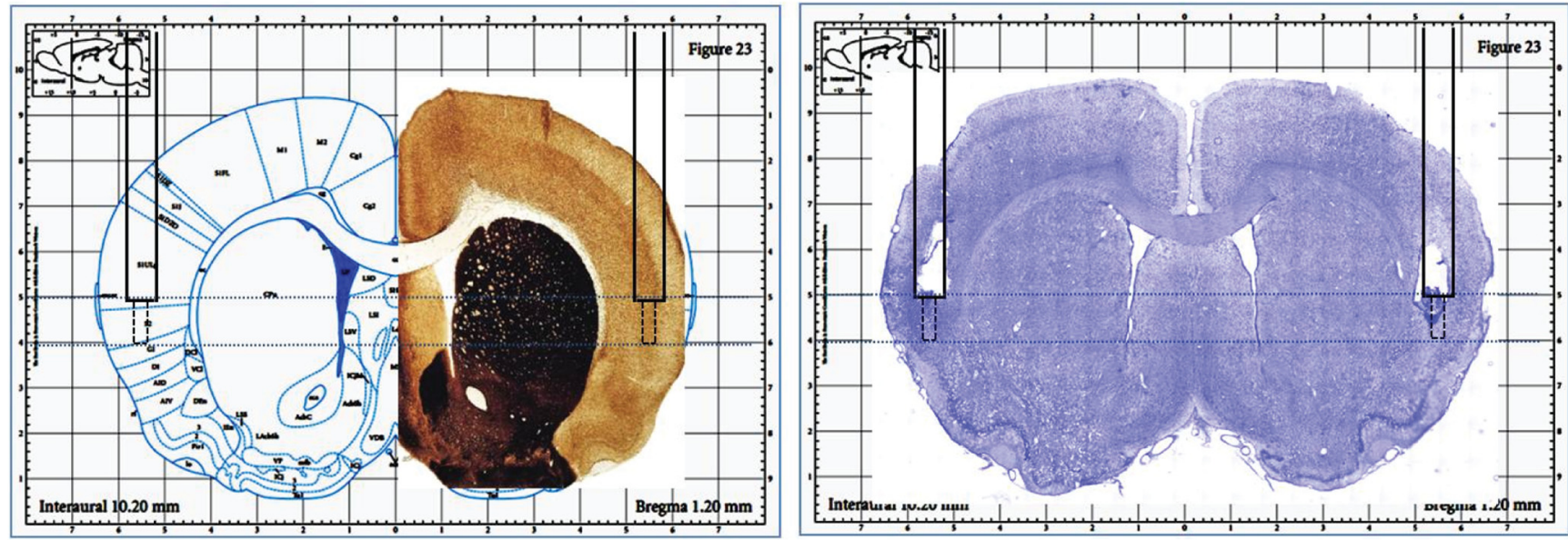

(Paxinos, G and Watson, C, 2006)

B

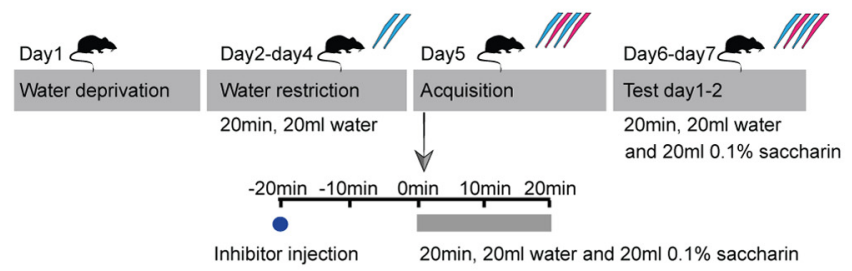

口Vehicle

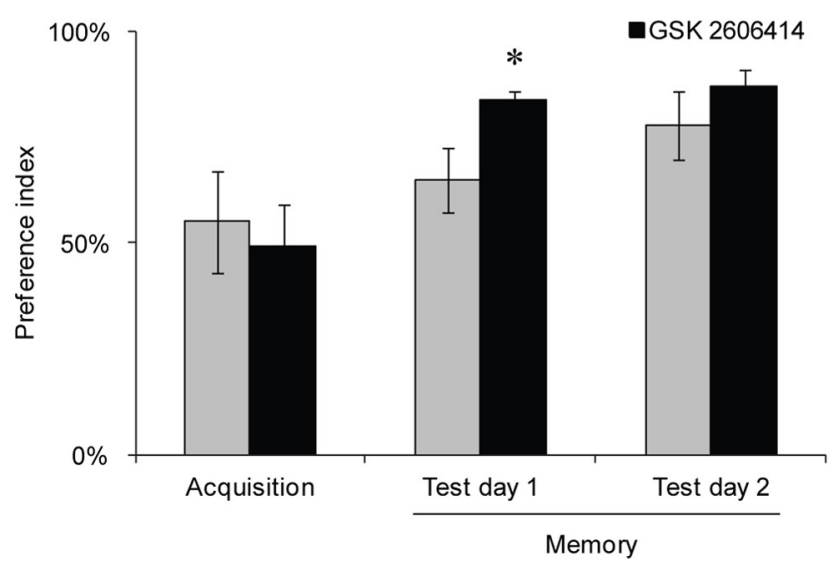

C
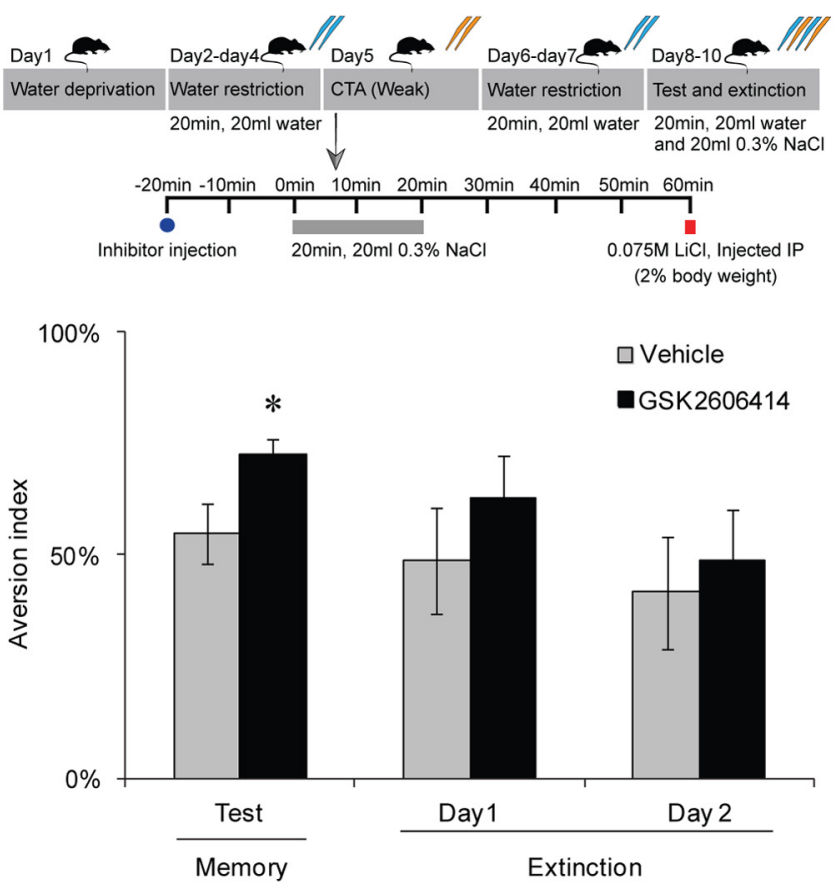

Figure 2. Local PERK inhibition (GSK2606414) in the IC enhances memory. $A$, A representative slice with Nissl staining shows the position of the cannula and the injection site. $\boldsymbol{B}$, Taste memory is enhanced following PERK inhibition. PERK inhibitor (GSK2606414, $100 \mathrm{~nm}$ ) was injected stereotaxically into the rat IC 20 min before novel taste drinking ( $0.1 \%$ saccharin). PERK inhibition enhances memory of the novel taste compared with vehicle group ( $n=8$ per group, $\left.{ }^{*} p=0.04\right)$. C, PERK inhibitor (GSK2606414) was injected 20 min before NaCl ( $\left.0.3 \%\right)$ drinking. CTA was performed as usual. PERK inhibition enhances CTA memory versus vehicle group, and extinction was not influenced $\left(n=8\right.$ per group, $\left.{ }^{*} p=0.04\right)$. Data are mean \pm SEM. Top diagrams are schematic description of the behavioral procedures. Blue pipettes indicate water. Red pipettes indicate saccharin. Yellow pipettes indicate $0.3 \% \mathrm{NaCl}$.

levels due to permanent expression of the shRNA cassette in a specific brain structure of the adult brain could result in different effects on behavior than those observed in the PERK cKO mice, where PERK is eliminated in the brain after weaning (Trinh et al., 2012). Therefore, the PERK shRNA lentivirus was stereotactically injected to the IC of adult rats, and its effects on taste memory were assessed using the novel taste learning and the CTA procedures $7 \mathrm{~d}$ following the injection (Fig. $3 A$ ). A representative image indicating virus injection site is shown in Figure $3 B$.

In the novel taste learning procedure, analysis of memory in the PERK knockdown animals over 2 consecutive days revealed a major group effect compared with the scrambled shRNA lentivirus controls, and the preference index was markedly elevated with taste familiarization from $28 \pm 5.1 \%$ on acquisition day to $48 \pm 5.6 \%$ and $57 \pm 5.1 \%$ on the two consecutive memory tests conducted $(n=21$ in each group, $Z=-2.798, p=0.005$, and $Z$ $=-3.285, p=0.001$ for test days 1 and 2 , respectively; Friedman test, followed by Wilcoxon signed-rank post hoc analysis, Bonferroni's correction; Fig. 3C). PERK knockdown in the IC also enhanced CTA memory as manifested by the elevation in the aversion index compared with scrambled sequence lentivirus controls $\left(81 \pm 2.2 \%\right.$ vs $55.9 \pm 4.7 \%, n=21$ in each group, $t_{(40)}=$ $-4.880, p=0.0003, t$ test). Interestingly, IC PERK knockdown not only enhanced CTA memory but also improved behavioral plasticity, as observed by the major group effect on CTA extinction on the 2 consecutive extinction days carried following the 
A

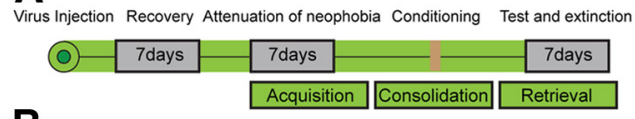

B
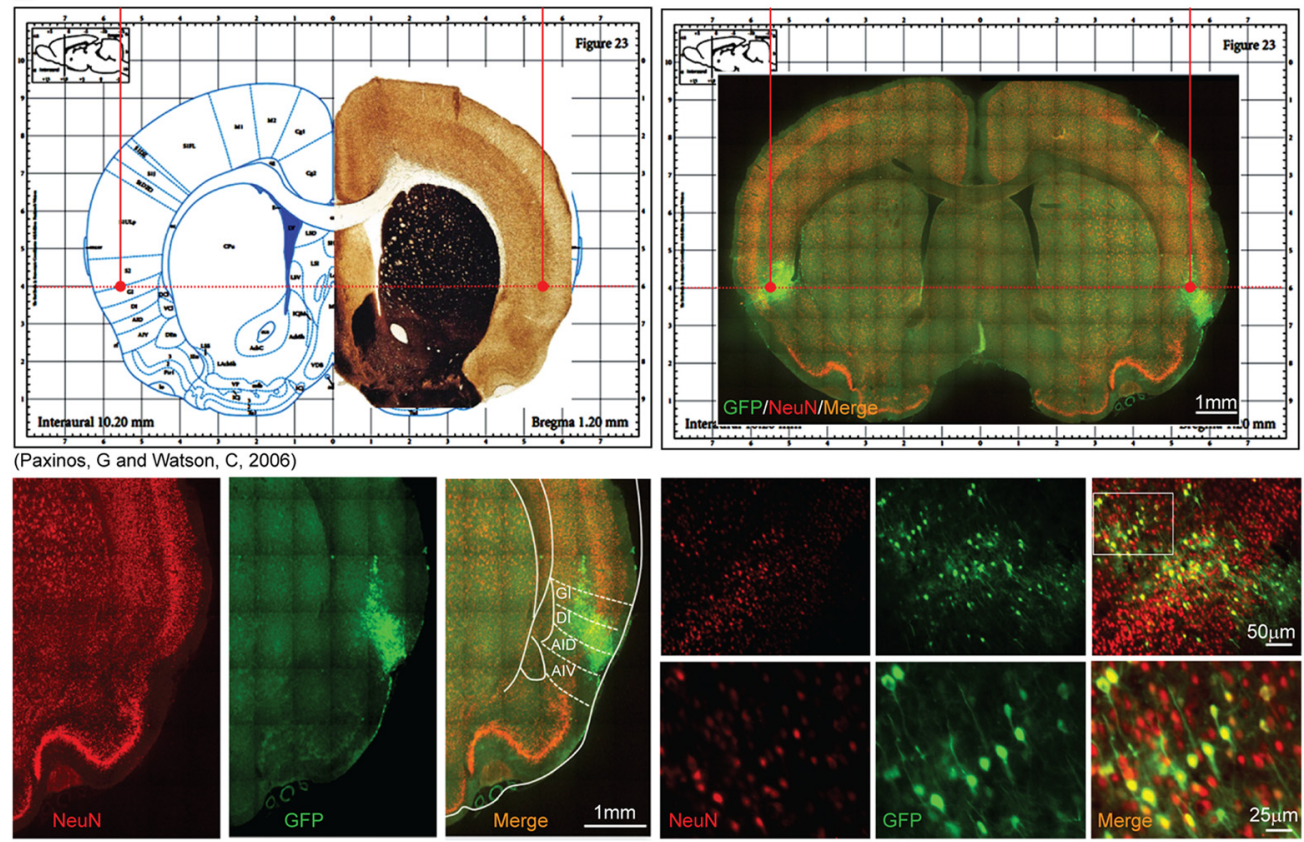

C
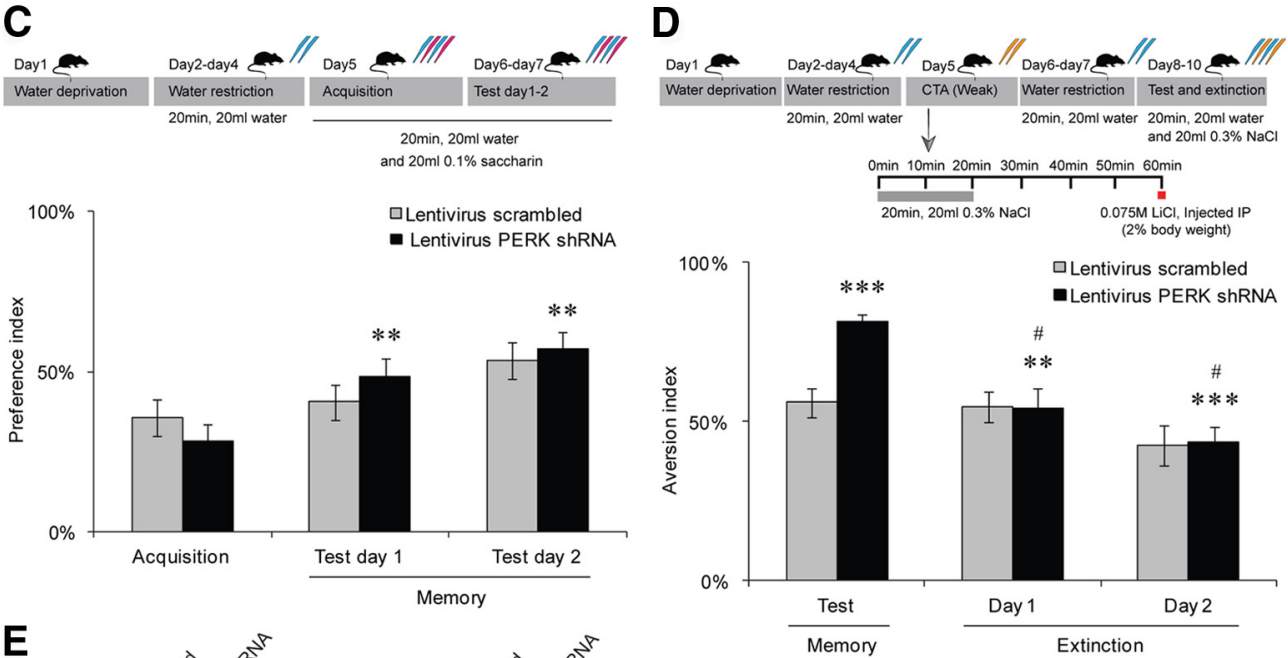

$\mathbf{E}$

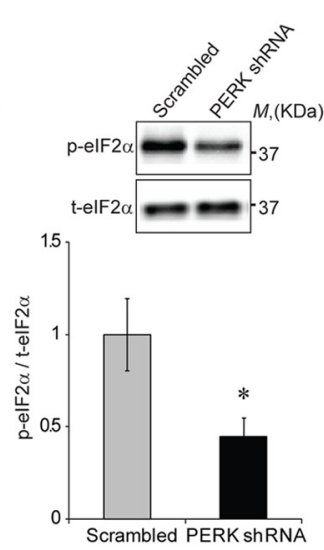

Figure 3. Knockdown of PERK in the IC enhances behavioral plasticity. $\boldsymbol{A}$, Schematic description of the experimental procedure. $\boldsymbol{B}$, A representative slice with neuronal nuclear staining (NeuN) colocalized with native GFP, indicating the virus injection site and proper expression. C, Novel taste ( $0.1 \%$ saccharin) learning is enhanced in PERK shRNA lentivirus-injected rats as expressed by the increase in preference index (PERK shRNA lentivirus, $n=21$; scrambled sequence control vector controls, $n=21,{ }^{* *} p=0.005$ for test day 1 , and $p=0.001$ for test day 2). $\boldsymbol{D}$, (TA memory is enhanced in PERK shRNA lentivirus-injected rats $(n=21)$ compared with scrambled sequence shRNA lentivirus-injected controls $(n=21)$. Extinction of CTA is improved in PERK shRNA lentivirus-injected rats, as demonstrated by the reduction in aversion index. Memory day, ${ }^{* * *} p=0.0003$; extinction of CTA, ${ }^{* * \#} p=0.001$ for day 1 extinction and (Figure legend continues.) 
CTA test $\left(F_{(1.724,34.486)}=20.410, p=\right.$ 0.01 , and 0.0001 for extinction days 1 and 2 respectively, repeated-measure ANOVA; Fig. 3D). Another set of animals was further tested for general, IC-independent behavioral flexibility in the arm reversal task using the water T-maze. Whereas CTA was enhanced in the PERK shRNA-injected rats as observed before ( $85 \pm 7.7 \%$ vs $59 \pm 8.7 \%$ in the control group, $n=6$ in each group, $t_{(10)}$ $=2.250, p=0.048, t$ test), both the scrambled and the PERK shRNA lentivirusinjected animals performed similarly in the reversal task. Total drinking volumes were similar in both experimental groups throughout the behavioral procedure (data not shown).

The effect of PERK knockdown on p-eIF $2 \alpha$ levels in the IC was determined by immunoblots from IC punches taken according to the coordinates of the injection site $(n=17$; Fig. $3 A)$. In accordance with our hypothesis, PERK levels and p-eIF2 $\alpha$ levels were significantly reduced in the IC punches made at the coordinates of the injection site (Fig. $3 E$ ). The reduction in p-eIF $2 \alpha$ levels was not only significant but also negatively correlated to the elevation in aversion index, indicative of improved memory (correlation value $r=$ $-0.55, n=14, p=0.04)$.

\section{PERK does not affect memory retrieval}

We next sought to determine whether the PERK-mediated effect of memory enhancement is the result of improved consolidation via the decrease in p-eIF2 $\alpha$ levels, or results from better retrieval. Therefore, the PERK shRNA lentivirus was injected to the IC $2 \mathrm{~d}$ after performing the CTA training $(0.3 \% \mathrm{NaCl}$ coupled to injection of $0.075 \mathrm{M} \mathrm{LiCl})$, and the memory test was performed 1 week following the virus injection (Fig. $4 A$ ). Our hypothesis was that if the effect is on learning itself, then PERK knockdown after learning would have no effect on memory, as learning occurred before virus injection and reduction in PERK expression.

Indeed, the PERK shRNA lentivirus-injected group had the same aversion (memory) as the scrambled shRNA lentivirusinjected group $(50.3 \pm 6 \%$ in PERK shRNA-injected group vs $54.9 \pm 9.9 \%$ in scrambled shRNA lentivirus group), clearly demonstrating that PERK knockdown and the resulting reduction in p-eIF2 $\alpha$ levels enhance memory by improving learning, but not by improving memory retrieval (Fig. $4 B$ ). As a control experiment, we divided the animals into two groups before virus injection, and performed novel taste learning. Clearly, we had no differences in the preference index between the two groups of naive animals, and total drinking volumes were similar in both

\section{$\leftarrow$}

(Figure legend continued.) 0.0001 for day 2 extinction. Data are mean \pm SEM. Top diagrams are schematic description of the behavioral procedure. Blue pipettes indicate water. Red pipettes indicate saccharin. Yellow pipettes indicate $0.3 \% \mathrm{NaCl}$. $\boldsymbol{E}$, Immunoblot analysis of the changes in PERK and $p$-elF2 $\alpha$ levels following virus injection to the IC demonstrates significant reduction in PERK levels (left, $n=12,{ }^{*} p=0.02$ ), and significant reduction in p-elF2 $\alpha$ levels (right, $n=$ $\left.17,{ }^{*} p=0.01\right)$. experimental groups throughout the behavioral procedure (data not shown).

\section{Discussion}

The results in this report demonstrate that under basal conditions PERK is the predominant kinase to determine p-eIF2 $\alpha$ levels (Fig. 1), and that PERK inhibition (using GSK2606414; Axten et al., 2012) or PERK knockdown (using a specific shRNA lentivirus) in the IC results in enhanced taste memory in both positive and negative forms of taste learning, namely incidental taste learning and CTA, respectively (Figs. 2, 3). Moreover, PERK knockdown results in improved CTA extinction, which indicates not only enhanced memory, but improved behavioral plasticity as well (Fig. 3). The improved behavioral plasticity was specific to IC-dependent behavior (taste learning and extinction), whereas the hippocampal-dependent T-maze arm reversal task was normal. In addition, the enhanced memory resulted from improved learning, as retrieval was not affected (Fig. 4).

The basal levels of p-eIF $2 \alpha$ in a specific brain area are determined by different variables, which include, among others, the amount and activity of the relevant kinases and phosphatases in different cell populations (i.e., neurons and non-neuronal cells) and subcellular localization. Using the viral vectors we reduced the expression of PERK, GCN2, and PKR in both the 3T3 cell line and primary neuronal culture. The strong reduction in GCN2 expression with no effect on p-eIF $2 \alpha$ allows us to conclude that GCN2 is not the major kinase to determine p-eIF2 $\alpha$ on the basal level. The relative contribution of PKR and PERK is less definitive, though in both cell lines and primary neuronal culture, 
PERK-reduced expression, compared to PKR reduced expression, clearly had a stronger and more significant effect on p-eIF2 $\alpha$. Interestingly, the half-life of PKR under basal conditions is $6.6 \mathrm{~h}$ (Liu et al., 2007), whereas the half-life of PERK is $13 \mathrm{~h}$ (Bertolotti et al., 2000). The changes in p-eIF2 $\alpha$ levels were measured 1 week following shRNA expression. Therefore, the changes in kinase expression levels are attributed to the efficacy of the shRNA applied and not initial differences in kinetics of synthesis and degradation, which are on a far shorter time scale. Importantly, the ultimate permanent absence of PKR expression in the PKR KO mice had no effect on p-eIF2 $\alpha$ (Stern et al., 2013), whereas PERK KO does have a significant clear reduction of p-eIF2 $\alpha$ (Ma et al., 2013). It remains to be clarified which neurotransmitters, neuronal patterns of activity, and signal transduction cascades control p-eIF $2 \alpha$ to enable better memory consolidation.

It was previously shown that taste learning induces reduction in p-eIF2 $\alpha$ levels, which is correlated with formation and enhancement of taste learning, and is also necessary for them (Stern et al., 2013). Taste learning was enhanced in the eIF2 $\alpha$ S51A KI mice, which express reduced levels of p-eIF2 $\alpha$ (Costa-Mattioli et al., 2007), and also following pharmacological inhibition of the eIF2 $\alpha$ kinase PKR (Stern et al., 2013). However, it was not clear whether the PKR inhibitor elicits memory enhancement by reducing p-eIF $2 \alpha$ levels or via other targets of PKR (Stern et al., 2013).

Translation regulation and the role of the eIF $2 \alpha$ kinases in longlasting synaptic plasticity and LTM have been extensively studied over the past decade (for review, see Trinh and Klann, 2013). Our knowledge regarding the role of the eIF $2 \alpha$ kinases in memory formation and cognitive function comes mainly from the kinase $\mathrm{KO}$ models (GCN2 KO, PKR KO, PERK cKO; Costa-Mattioli et al., 2005; Zhu et al., 2011; Trinh et al., 2012; Stern et al., 2013). Interestingly, the phenotypes of these mice are complex on the biochemical, electrophysiological, and behavioral levels. For example, the PKR KO mice exhibit facilitated late-phase LTP (L-LTP) and LTM, and PKR is believed to control gene-specific translation, such as IFN $\gamma$ specifically in GABAergic cells or BDNF in CA1 pyramidal cells (Costa-Mattioli et al., 2005; Jiang et al., 2010; Zhu et al., 2011; Trinh and Klann, 2013). In GCN2 KO mice, the threshold for L-LTP is lowered, whereas mGluR-LTD is unaffected. This effect seems to be mediated by GCN2-dependent ATF4 translation, which is associated with a lower threshold for activation of CREB-mediated gene expression (Costa-Mattioli et al., 2005). In PERK KO mice, the reduction in p-eIF2 $\alpha$ levels and ATF4 translation did not alter the threshold for LTP, as opposed to the lower threshold for induction in GCN2-deficient mice. In contrast, mGluR-LTD, which is protein synthesis dependent and unaffected in GCN2-deficient mice, was enhanced in PERK cKO mice, suggesting the interesting possibility that distinct pools of mRNA may be differentially translated during protein synthesis-dependent forms of LTP and LTD (for review, see Trinh and Klann, 2013). On the behavioral level, the GCN2 and PKR KO mice exhibit improved hippocampal LTM under weak training protocols, whereas the behavioral phenotype of the PERK KO mice consists of impaired information processing and behavioral flexibility (Costa-Mattioli et al., 2005; Zhu et al., 2011; Trinh et al., 2012; Stern et al., 2013).

On the biochemical level, the kinases are known to exert their effect on translation regulation by phosphorylating the Ser51 of eIF2 $\alpha$ in response to various cellular stressors (Trinh and Klann, 2013), and reduced phosphorylation on Ser 51 of eIF $2 \alpha$ enhances memory and improves synaptic plasticity (Costa-Mattioli et al., 2007; Stern et al., 2013). However, the various eIF2 $\alpha$ kinase KO models have produced conflicting data in respect to their contribution to p-eIF $2 \alpha$ and how this mediates memory enhancement.
The GCN2 and PKR KO mice are general prenatal knockouts, whereas the PERK KO is under the CaMKII promoter, and is expressed postnatally in the forebrain, further suggesting that the differences observed in the phenotypes of these mice could be developmental or can be attributed to different roles of the kinases in specific brain subregions or in cell subtypes.

This notion further emphasizes the need to examine the role of each kinase in a spatial-specific manner in the adult brain to determine its role in LTM and in synaptic and behavioral plasticity. More specifically, whereas postnatal deletion of PERK in the forebrain results in a wide spectrum of behavioral inflexibility (Trinh et al., 2012), our results demonstrate that reduction of its expression in the adult brain, restricted to a specific cortical area, results in enhanced memory and improved extinction, reflecting better behavioral flexibility (Fig. 3).

A recent study demonstrated that PERK-directed translational control of p-eIF $2 \alpha$ distinctly limits the expression of mGluR-dependent LTD in the hippocampus (Trinh et al., 2014), and future studies investigating the specific role of PERKregulated translation in different brain regions and neuronal populations will prove useful to elucidate the molecular mechanisms underlying normal and abnormal cognitive processes. Indeed, altered p-eIF $2 \alpha$ levels have been reported in various brain diseases. These neurological disorders and neurodegenerative diseases include Alzheimer's disease, Parkinson's disease, fragile $\mathrm{X}$ syndrome, tuberous sclerosis complex, autism spectrum disorder, and prion disease, all involving the accumulation of misfolded proteins, and consequently endoplasmic reticulum stress (Kelleher and Bear, 2008; Ozcan et al., 2008; Auluck et al., 2010; Hoeffer and Klann, 2010; Palop and Mucke, 2010; Santini and Klann, 2011; Moreno et al., 2012). Reduced p-eIF2 $\alpha$ is involved in psychiatric disorders, such as schizophrenia (Trinh et al., 2012). PERK phosphorylates eIF $2 \alpha$ in response to accumulation of misfolded proteins, and is a key regulator of the UPR. For these reasons, PERK has emerged as a promising target for treating neurodegeneration. Nevertheless, general brain manipulation of PERK expression via genetic methods has also demonstrated that UPR activation can directly contribute to cognitive dysfunction (Trinh et al., 2012). This raises the tantalizing prospect of a general treatment for brain diseases, independent of any diseasespecific mechanisms (Halliday and Mallucci, 2014).

The eIF $2 \alpha$ kinases are nowadays highlighted as promising potential targets for pharmaceutical development of novel therapies to various brain diseases. Nevertheless, the notion that eIF2 $\alpha$ kinases have a differential contribution not only to p-eIF $2 \alpha$ levels but also to different behaviors, based on different cell types and brain regions, requires comprehensive thinking regarding the human adult brain, and demands an effort to develop specific remedies to specific brain regions and specific disease characteristics. This raises the possibility that gene therapy using viral vectors is advantageous in tackling brain disease, as it circumvents global effects on the brain, and makes it possible to perform specific modifications in specific cells within specific brain regions. Consistent with these findings, our results emphasize the critical importance of PERK in normal cognitive processes. Further studies elucidating the specific role of PERKregulated translation in the brain may provide new avenues to tackle such widespread and often debilitating neurological disorders.

\section{References}

Antion MD, Merhav M, Hoeffer CA, Reis G, Kozma SC, Thomas G, Schuman EM, Rosenblum K, Klann E (2008) Removal of S6K1 and S6K2 leads to divergent alterations in learning, memory, and synaptic plasticity. Learn Mem 15:29-38. CrossRef Medline 
Auluck PK, Caraveo G, Lindquist S (2010) Alpha-synuclein. Membrane interactions and toxicity in Parkinson's disease. Annu Rev Cell Dev Biol 26:211-233. CrossRef Medline

Axten JM, Medina JR, Feng Y, Shu A, Romeril SP, Grant SW, Li WH, Heerding DA, Minthorn E, Mencken T, Atkins C, Liu Q, Rabindran S, Kumar R, Hong X, Goetz A, Stanley T, Taylor JD, Sigethy SD, Tomberlin GH, et al. (2012) Discovery of 7-methyl-5-(1-\{[3-(trifluoromethyl)phenyl $]$ acetyl $\}$ -2,3-dihydro-1H-indol-5-yl)-7H-pyrrolo[2,3-d]pyrimidin-4-amine (GSK2606414), a potent and selective first-in-class inhibitor of protein kinase R (PKR)-like endoplasmic reticulum kinase (PERK). J Med Chem 55:7193-7207. CrossRef Medline

Barki-Harrington L, Elkobi A, Tzabary T, Rosenblum K (2009) Tyrosine phosphorylation of the 2B subunit of the NMDA receptor is necessary for taste memory formation. J Neurosci 29:9219-9226. CrossRef Medline

Belelovsky K, Elkobi A, Kaphzan H, Nairn AC, Rosenblum K (2005) A molecular switch for translational control in taste memory consolidation. Eur J Neurosci 22:2560-2568. CrossRef Medline

Belelovsky K, Maroun M, Rosenblum K (2007) MAPK activation in the hippocampus in vivo is correlated with experimental setting. Neurobiol Learn Mem 88:58-64. CrossRef Medline

Belelovsky K, Kaphzan H, Elkobi A, Rosenblum K (2009) Biphasic activation of the mTOR pathway in the gustatory cortex is correlated with and necessary for taste learning. J Neurosci 29:7424-7431. CrossRef Medline

Bertolotti A, Zhang Y, Hendershot LM, Harding HP, Ron D (2000) Dynamic interaction of BiP and ER stress transducers in the unfoldedprotein response. Nat Cell Biol 2:326-332. CrossRef Medline

Costa-Mattioli M, Gobert D, Harding H, Herdy B, Azzi M, Bruno M, Bidinosti M, Ben Mamou C, Marcinkiewicz E, Yoshida M, Imataka H, Cuello AC, Seidah N, Sossin W, Lacaille JC, Ron D, Nader K, Sonenberg N (2005) Translational control of hippocampal synaptic plasticity and memory by the eIF2alpha kinase GCN2. Nature 436:1166-1173. CrossRef Medline

Costa-Mattioli M, Gobert D, Stern E, Gamache K, Colina R, Cuello C, Sossin W, Kaufman R, Pelletier J, Rosenblum K, Krnjević K, Lacaille JC, Nader K, Sonenberg N (2007) eIF2alpha phosphorylation bidirectionally regulates the switch from short- to long-term synaptic plasticity and memory. Cell 129:195-206. CrossRef Medline

Edry E, Lamprecht R, Wagner S, Rosenblum K (2011) Virally mediated gene manipulation in the adult CNS. Front Mol Neurosci 4:57. CrossRef Medline

Elkobi A, Ehrlich I, Belelovsky K, Barki-Harrington L, Rosenblum K (2008) ERK-dependent PSD-95 induction in the gustatory cortex is necessary for taste learning, but not retrieval. Nat Neurosci 11:1149-1151. CrossRef Medline

Gal-Ben-Ari S, Rosenblum K (2011) Molecular mechanisms underlying memory consolidation of taste information in the cortex. Front Behav Neurosci 5:87. CrossRef Medline

Gal-Ben-Ari S, Kenney JW, Ounalla-Saad H, Taha E, David O, Levitan D, Gildish I, Panja D, Pai B, Wibrand K, Simpson TI, Proud CG, Bramham CR, Armstrong JD, Rosenblum K (2012) Consolidation and translation regulation. Learn Mem 19:410-422. CrossRef Medline

Gildish I, Manor D, David O, Sharma V, Williams D, Agarwala U, Wang X, Kenney JW, Proud CG, Rosenblum K (2012) Impaired associative taste learning and abnormal brain activation in kinase-defective eEF2K mice. Learn Mem 19:116-125. CrossRef Medline

Gkogkas C, Sonenberg N, Costa-Mattioli M (2010) Translational control mechanisms in long-lasting synaptic plasticity and memory. J Biol Chem 285:31913-31917. CrossRef Medline

Halliday M, Mallucci GR (2014) Targeting the unfolded protein response in neurodegeneration. A new approach to therapy. Neuropharmacology 76: 169-174. CrossRef Medline

Hoeffer CA, Klann E (2010) mTOR signaling. At the crossroads of plasticity, memory and disease. Trends Neurosci 33:67-75. CrossRef Medline

Hooper C, Markevich V, Plattner F, Killick R, Schofield E, Engel T, Hernandez F, Anderton B, Rosenblum K, Bliss T, Cooke SF, Avila J, Lucas JJ, Giese KP, Stephenson J, Lovestone S (2007) Glycogen synthase kinase-3 inhibition is integral to long-term potentiation. Eur J Neurosci 25:81-86. CrossRef Medline

Inberg S, Elkobi A, Edri E, Rosenblum K (2013) Taste familiarity is inversely correlated with Arc/Arg3.1 hemispheric lateralization. J Neurosci 33: 11734-11743. CrossRef Medline

Jiang Z, Belforte JE, Lu Y, Yabe Y, Pickel J, Smith CB, Je HS, Lu B, Nakazawa $\mathrm{K}$ (2010) eIF2 $\alpha$ phosphorylation-dependent translation in CA1 pyrami- dal cells impairs hippocampal memory consolidation without affecting general translation. J Neurosci 30:2582-2594. CrossRef Medline

Kelleher RJ 3rd, Bear MF (2008) The autistic neuron. Troubled translation? Cell 135:401-406. CrossRef Medline

Liu WL, Su WC, Cheng CW, Hwang LH, Wang CC, Chen HL, Chen DS, Lai MY (2007) Ribavirin up-regulates the activity of double-stranded RNAactivated protein kinase and enhances the action of interferon-alpha against hepatitis C virus. J Infect Dis 196: 425-434. CrossRef Medline

Lois C, Hong EJ, Pease S, Brown EJ, Baltimore D (2002) Germline transmission and tissue-specific expression of transgenes delivered by lentiviral vectors. Science 295:868-872. CrossRef Medline

Ma T, Trinh MA, Wexler AJ, Bourbon C, Gatti E, Pierre P, Cavener DR, Klann E (2013) Suppression of eIF2alpha kinases alleviates alzheimer's disease-related plasticity and memory deficits. Nat Neurosci 16:12991305. CrossRef Medline

Merhav M, Rosenblum K (2008) Facilitation of taste memory acquisition by experiencing previous novel taste is protein-synthesis dependent. Learn Mem 15:501-507. CrossRef Medline

Merhav M, Kuulmann-Vander S, Elkobi A, Jacobson-Pick S, Karni A, Rosenblum K (2006) Behavioral interference and C/EBPbeta expression in the insular-cortex reveal a prolonged time period for taste memory consolidation. Learn Mem 13:571-574. CrossRef Medline

Moreno JA, Radford H, Peretti D, Steinert JR, Verity N, Martin MG, Halliday M, Morgan J, Dinsdale D, Ortori CA, Barrett DA, Tsaytler P, Bertolotti A, Willis AE, Bushell M, Mallucci GR (2012) Sustained translational repression by eIF $2 \alpha$-P mediates prion neurodegeneration. Nature 485:507511. CrossRef Medline

O'Connor T, Sadleir KR, Maus E, Velliquette RA, Zhao J, Cole SL, Eimer WA, Hitt B, Bembinster LA, Lammich S, Lichtenthaler SF, Hébert SS, De Strooper B, Haass C, Bennett DA, Vassar R (2008) Phosphorylation of the translation initiation factor eIF2alpha increases BACE1 levels and promotes amyloidogenesis. Neuron 60:988-1009. CrossRef Medline

Ozcan U, Ozcan L, Yilmaz E, Düvel K, Sahin M, Manning BD, Hotamisligil GS (2008) Loss of the tuberous sclerosis complex tumor suppressors triggers the unfolded protein response to regulate insulin signaling and apoptosis. Mol Cell 29:541-551. CrossRef Medline

Palop JJ, Mucke L (2010) Amyloid-beta-induced neuronal dysfunction in Alzheimer's disease. From synapses toward neural networks. Nat Neurosci 13:812-818. CrossRef Medline

Paxinos G, Watson C (2006) The rat brain in stereotaxic coordinates, 6th ed. San Diego: Elsevier.

Rosenblum K, Meiri N, Dudai Y (1993) Taste memory. The role of protein synthesis in gustatory cortex. Behav Neural Biol 59:49-56. CrossRef Medline

Santini E, Klann E (2011) Dysregulated mTORC1-dependent translational control. From brain disorders to psychoactive drugs. Front Behav Neurosci 5:76. CrossRef Medline

Sonenberg N, Dever TE (2003) Eukaryotic translation initiation factors and regulators. Curr Opin Struct Biol 13:56-63. CrossRef Medline

Stern E, Chinnakkaruppan A, David O, Sonenberg N, Rosenblum K (2013) Blocking the eIF2 $\alpha$ kinase (PKR) enhances positive and negative forms of cortex-dependent taste memory. J Neurosci 33:2517-2525. CrossRef Medline

Trinh MA, Klann E (2013) Translational control by eIF2alpha kinases in long-lasting synaptic plasticity and long-term memory. Neurobiol Learn Mem 105:93-99. CrossRef Medline

Trinh MA, Kaphzan H, Wek RC, Pierre P, Cavener DR, Klann E (2012) Brain-specific disruption of the eIF2alpha kinase PERK decreases ATF4 expression and impairs behavioral flexibility. Cell Rep 1:676-688. CrossRef Medline

Trinh MA, Ma T, Kaphzan H, Bhattacharya A, Antion MD, Cavener DR, Hoeffer CA, Klann E (2014) The eIF2 $\alpha$ kinase PERK limits the expression of hippocampal metabotropic glutamate receptor-dependent longterm depression. Learn Mem 21:298-304. CrossRef Medline

Yefet K, Merhav M, Kuulmann-Vander S, Elkobi A, Belelovsky K, Jacobson-Pick S, Meiri N, Rosenblum K (2006) Different signal transduction cascades are activated simultaneously in the rat IC and hippocampus following novel taste learning. Eur J Neurosci 24:1434-1442. CrossRef Medline

Zhu PJ, Huang W, Kalikulov D, Yoo JW, Placzek AN, Stoica L, Zhou H, Bell JC, Friedlander MJ, Krnjević K, Noebels JL, Costa-Mattioli M (2011) Suppression of PKR promotes network excitability and enhanced cognition by interferon-gamma-mediated disinhibition. Cell 147:1384-1396. CrossRef Medline 